\title{
Nursing team and promotion of humanized care in a neonatal unit*
}

\author{
Equipe de enfermagem e promoção do cuidado humanizado em unidade neonatal
}

José Hernevides Pontes Ferreiraํㅜ, João Joaquim Freitas do Amaral², Márcia Maria Coelho Oliveira Lopes²

Objective: to understand the knowledge and actions of the nursing team about humanized care in a Neonatal Intensive Care Center. Methods: qualitative research carried out with 14 nurses and 20 nursing technicians working in a public institution. Semi-structured interview and content analysis were applied. Results: three thematic categories emerged: Humanized care to the newborn; Welcoming the newborn's family and Promotion of the neonatal environment. The work of the Nursing team showed they have technical-scientific knowledge, humanized skills and attitudes that provided the recovery of the newborn's health, minimized the stressors in the neonatal environment, as well as fostered family relationships and establishment of bond during the process of taking care. Conclusion: the acquisition of knowledge about humanized care implied a greater commitment, sensitivity and zeal in the art of taking care, emphasizing, above all, actions of comfort, newborn safety, welcoming to the family and attention in the ambience.

Descriptors: Infant, Newborn; Neonatal Nursing; Humanization of Assistance; Nursing Care.

Objetivo: compreender conhecimentos e ações da equipe de enfermagem acerca do cuidado humanizado em Centro de Terapia Intensiva Neonatal. Métodos: pesquisa qualitativa, realizada com 14 enfermeiros e 20 técnicos de enfermagem atuantes em uma instituição pública. Aplicou-se entrevista semiestruturada com análise de conteúdo. Resultados: emergiram três categorias temáticas: Atenção humanizada ao recém-nascido; Acolhimento à família do recém-nascido e Promoção da ambiência neonatal. A atuação da equipe de Enfermagem demonstrou conhecimento técnico-científico, habilidades e atitudes humanizadas que proporcionaram a recuperação da saúde do recém-nascido, minimizaram os fatores estressantes no ambiente neonatal, além de promover acolhimento aos familiares e o estabelecimento do vínculo durante o processo de cuidar. Conclusão: a aquisição dos conhecimentos acerca do cuidado humanizado implicou maior comprometimento, sensibilidade e zelo na arte de cuidar, destacando, sobretudo, ações de conforto, segurança do recém-nascido, acolhimento à família e atenção na ambiência.

Descritores: Recém-Nascido; Enfermagem Neonatal; Humanização da assistência; Cuidados de Enfermagem.

\footnotetext{
*Extracted from the Dissertation: “Percepção da equipe de enfermagem sobre o cuidado humanizado em Unidade Neonatal”, Universidade Federal do Ceará, 2016.

${ }^{1}$ Hospital Infantil Albert Sabin. Fortaleza, CE, Brazil.

${ }^{2}$ Universidade Federal do Ceará. Fortaleza, CE, Brazil. 


\section{Introduction}

The newborn with his or her affected needs is abruptly separated from the mother and referred to the Neonatal Intensive Care Unit, where they remain exposed to excessive manipulation, painful stimuli, illumination, noise and unstable temperature, which portrays an inhospitable and hostile environment ${ }^{(1)}$.

Hospitalization involves specialized treatment with the use of complex technologies; however, the parents experience an embarrassing situation, marked by feelings of fear, insecurity and tension, when faced with the image of the child hospitalized in this frightening environment ${ }^{(2)}$. Faced with such circumstances, the nursing team should offer support and welcome to parents to ease conflicts and stressful moments ${ }^{(3-4)}$.

In order to meet the axis of action in the neonatal units, the Brazilian Ministry of Health has introduced new paradigms in the health system, such as the implementation of the National Humanization Policy that envisions the humanized care model, involving health professionals, as caregivers, who are responsible by changes in their actions ${ }^{(5)}$. It is noteworthy that the policy of humanization at birth, puerperium and risk neonatal care has innovated traditional care for preterm and low birth weight infants $^{(6)}$.

From this perspective, the literature addresses the technological advances, the improvement of technical conducts ${ }^{(7-8)}$, as well as the ethics and competence of professionals who have greatly favored the promotion of the quality of comprehensive care for the newborn and the family ${ }^{(9-10)}$. It should be emphasized that in contemporary nursing, technologies in health care have favored improved human care, contributing significantly to human survival(1).

From this therapeutic evolution, the universe of modern and qualified care has been broadened, which identifies the milestone in neonatal care. In addition, it can be seen that nurses seek in their practice the application of humanized care with emphasis on interpersonal relationships ${ }^{(3,10)}$, effective communication between the newborn and their family ${ }^{(11)}$, as well as crucial strategies that involve environmental ecology ${ }^{(12)}$.

In search for optimization of care, the studies that address the humanization of care show the relationships established between managers, professionals, clients and families, whose professional team, imbued with commitment and responsibility, develops welcoming, comfort and safety practices ${ }^{(13)}$, in a way that promotes the establishment of affective bond between parents and neonates ${ }^{(8)}$.

The interest in this theme coincides with the awakening for the Nursing care practice based on humanization, as well as the scientific evidence that signals the advancement of neonatal care, highlighting the innovations and sophisticated technologies for clinical management and baby care. It is believed that in order to achieve quality of care, it is necessary for the nursing team to seek improvement and to be updated in the perspective of the humanization of care.

Considering the importance of humanization strategies in the care for the newborn at risk, this study is based on the following questions: what are the knowledge and skills that the nursing team develops in the humanized care in the neonatal unit? Does the nursing team provide care for newborns and their parents, according to the humanization proposal devised by the Brazilian Ministry of Health?

The research is relevant as it contributes to the awakening of the practice of health professionals in the area of Neonatology, seeking to promote quality care, based on the National Humanization Policy. In this perspective, the objective was to understand the knowledge and actions of the nursing team about the humanized care in a Neonatal Intensive Care Center. 


\section{Methods}

This is a qualitative study, carried out in a public hospital of tertiary care for children and adolescents, in Fortaleza, Brazil. The research scenario was a Neonatal Intensive Care Center, which consists of 12 beds for the admission of newborns with diagnoses of prematurity, very low weight, perinatal asphyxia, malformations, with highlight to heart diseases, chromosomal anomalies, among others.

The sample consisted of 14 nurses and 20 nursing technicians who met the following inclusion criteria: nursing professionals who have been working in the unit for a minimum period of one year, regardless of the employment relationship and who were in the service schedule during the collection period, which comprised October and November 2015. It should be noted that this team was composed of 17 nurses and 30 nursing technicians; however, four were on vacation and two, on medical leave.

As a collection technique, authors applied a semi-structured interview, consisting of the subjects' characterization items (gender, age, marital status, qualification, years of training and time of work in the unit) and three open questions concerning the provision of humanized care to the baby, to the parents and neonatal environment. The interview was applied by one of the authors of the study, covering the three shifts (morning, afternoon and night), in a reserved place, which guaranteed privacy, and with an average duration of 20 to 30 minutes.

Researchers opted for the Content Analysis technique in thematic modality, which allows us to explore several representations of reality in the light of a certain theoretical methodological framework. This technique addresses three different steps: preanalysis or material organization; exploration of this material through classification and categorization, as well as interpretation of the results ${ }^{(14)}$, triggering reflections on the intended objectives.
In compliance with the ethical and legal aspects of the research, anonymity was adopted by the coding of the initials of Nurse (N), Nursing Technician (T) and a numerical sequence, according to the order of interview.

The study complied with the formal requirements contained in the national and international regulatory standards for research involving human beings.

\section{Results}

Data analysis allowed obtaining the profile of participants and the aspects that involve the humanized care of the nursing professionals to the newborn hospitalized in a neonatal unit, expressed in three empirical categories: Humanized care to the newborn, Welcoming the newborn's family and Promotion of the neonatal environment.

Of the 34 nursing professionals who participated, there was higher frequency of women in the groups of nursing technicians $(100.0 \%)$ and nurses (99.0\%). Regarding the characteristics of nurses, seven were married, five were single and two were in consensual union. The majority were between two age groups from 41 to 50 years (14.3\%) and more than 61 years old (14.3\%). About the training time, five $(35.7 \%)$ nurses stood out with 21 to 30 years of training and four (28.6\%), with 1 to 10 years. As regards the time of work, six (42.8\%) stood out,, with 21 to 30 years of work, and regarding the time of work in the studied institution, two groups represented four (28.6\%) between 1 and 10 years and 21 and 30 years, respectively.

In the group of 20 nursing technicians, the majority was married (70.0\%), within two age groups, from 41 to 50 years (30.0\%) and from 51 to 60 years $(30.0 \%)$, the prevalent time of work ranged from 11 and 20 years (35.0\%), and in relation to the time of work in this sector, there was highlight for the 
intervals between 1 to 10 years (28.6\%) and 21 to 30 years $(28.6 \%)$.

\section{Category 1: Humanized care to the newborn}

This category expresses the statements that approach knowledge, skills and attitudes in the care, considered basic instruments inherent in the nursing profession. In order to know how this team provides humanized care to the newborn in the neonatal unit, the responses evidence more success in the actions that involve the affected needs and, therefore, individual care.

This approach refers to the provision of care with affection, respect to the singularities of each one, promoting care to the baby consciously and responsibly, as demonstrated in the speeches: I try to identify signs of pain (N12). We should prioritize the sleep time, keeping the silence (N1). Using the oximeter in the newborn to avoid burns (N14). Keeping the baby well wrapped to avoid heat loss (T10). Positioning the baby correctly without elevating the lower limbs (T12).

The professionals emphasized their practice, showing themselves capable of providing individualized and humanized care, which is essential to the survival and recovery of babies' health. The care offered to the neonate is expanded beyond technical care, scientific knowledge, as it is verified: I avoid handling too much, especially when they are premature (N1) ... providing comfort inside the incubator, warming their hands (N2). Minimum handling and I take advantage of the procedures to do them in a single moment (T7). Hand hygiene (T9).

Through the mentioned practices, we can identify care practices regarding comfort, protection of the baby and attention to the specificities of humanized care. Therefore, the sensitivity of the nursing team portrays care with zeal and respect, which are important for human well-being and quality of life, as described: Checking alarms promptly (N3); Avoid talking, talking low (N7). Being careful of incubator hatches (T4). Organizing the baby in the incubator (T10). Touching the baby, touching their head and talking softly with them (T18).
The nursing team emphasized the importance of the presence of parents in the neonatal unit, since it values the establishment of attachment and bond between parents and child, as well as the participation in the therapeutic and care process.

\section{Category 2: Welcoming the newborn's family}

The humanization of care involves the participation of the family in the baby's hospitalization, during which professionals should prepare the parents to participate in the caring process. In this study, the researcher observed empathy and respect during a meeting between professionals, neonates and family, as this is an opportune moment that benefits the identification of needs, establishment of the affective bond, as well as provides confidence to take care of the child.

The nursing team welcomes families with necessary guidelines regarding institutional routines and doubts about the disease and treatment, resulting in an approximation between professionals and families, which strengthens the affective bonds, as well as attenuates negative effects of hospitalization. This demonstrates the commitment and awareness of some professionals, as evidenced: Welcoming the mother during hospitalization favors the bond between mother and baby (N8). Welcoming the newborn and their family upon admission strengthens communication (T9). I transmit care and zeal to the newborn to provide safety to the mother (T18).

Another aspect addressed by the interviewees relates to oral expression and dedication to parents, in a preparation that empowers them as caregivers, enabling the continuity of care. It was revealed both in the posture and in the description of the professionals' activities the awareness about the humanized care to the baby and extended to the parents: ... I offer care with affection, affection and dialogue with those parents who arrive so afflicted (N7). I always try to call the mother when I clean the baby and explain it step by step (T7).... I realize that the mother is interested and becomes more cheerful when I explain it (T9). I encourage the mother to touch her baby when she arrives at the unit (T15). 
Assisting the hospitalized newborn's family is responsibility of the interdisciplinary team of the hospitalization unit, especially the nursing staff, who remains full-time in caring for the newborn. The caregiver team includes the parents of the hospitalized newborn as agents of the caring process, demonstrating such attitudes: I transmit information clearly to the family (N5). I try to give strength to the mother, when she is distressed, with easy crying (T10). I talk with parents about continuation of baby care when going home (T14) ... I transmit to the family when the newborn will be submitted to any invasive procedure (T17).

Thus, the nursing team is sensitive to the fragility of the parents affected by the impaired health and recovery of the hospitalized child. The speeches reveal the involvement between the team, the baby and the family, from the care centered on the needs of the newborn, identification of the feelings, values and difficulties of the parents, as well as the search for measures that minimize the suffering and pain of the family.

In this sense, the interviewees mentioned the importance of a welcoming assistance, considering the influence of interaction and communication, which are essential to make the parents adapted and involved in the care.

\section{Category 3: Promotion of the neonatal environ- ment}

Regarding the environment, when asked about the promotion of humanized care, professionals reported attention to the complex characteristics of the unit and the impacts on the behavioral reactions of the babies, as follows: Watching for alarms and monitors (N1). Avoiding noise from aspirators that sometimes keep connected after procedures (T7). I try to reduce noise and clarity; I ask the staff to heed the alarms (T14). Sometimes the incubator alarms can indicate high temperature and the baby gets agitated and cries a lot (T17).

In addition to these strategies, the professionals focused their attention on the humanization of care and, with a focus on the technological aspects, they minimized the negative impact of the stressful environment of the neonatal intensive care unit, planned and executed comprehensive care according to the individualized needs of each baby: We must be subtle when opening the incubator door (N1).... talk low and keep the baby space organized (N3). I ask the team to tone down the voice (T18). I try to raise awareness that excessive noise will bring harm to the newborn (T19).

In this work process, the nursing team demonstrated the promotion of humanized care in relation to the neonatal environment, becoming it a more welcoming place, unlike the traditional model of care.

\section{Discussion}

The humanization approach in neonatal care refers to the elaboration of public policies developed in Brazil and, in turn, over the last decades, there has been a significant impact on the health care and survival of preterm and low birth weight infants. In addition, it has created a preponderant role in the professionals' practice in various scenarios of the hospital care of the Brazilian Unified Health System ${ }^{(15)}$, above all in the ways of managing and providing care.

With the implementation of humanized care for the newborn, professionals have advocated interventions that refer to the individuality and comprehensiveness of care, guarantee of technology for the recovery and safety of the newborn, welcome to the family, establishing of bonding and attachment, among others ${ }^{(6)}$. A study on humanization of care showed similar results and emphasized the importance of establishing communication and interaction in an effective and affective way, throughout the care process $^{(11)}$.

The humanization strategies addressed in the Brazilian literature have highlighted communication as an instrument that mediates humanized care $^{(7,11)}$, the affective touch that shows affection, empathy and closeness between parents, child and professionals ${ }^{(4,7,9)}$, the kangaroo position (skin-to- 
skin contact) that promotes affectivity and weight gain, encourages breastfeeding as early as possible ${ }^{(16)}$, extending the themes with the interventions that permeate the safety measures in all care processes.

The present study evidenced the commitment of professionals in the care of the newborn, with emphasis in attitudes of zeal and safety, respect for the individuality and its specificities, as well as efforts to maximize care, insertion of the family in the care process, minimization of risks that are inherent to the medical-therapeutic procedures and neonatal environment. Therefore, there has been progress in care regarding the access of parents to the hospitalization unit, predominantly the mother, besides special attention to procedures and environment, which are aspects recommended by the National Humanization Policy.

Considering safety as a basic principle and requirement for quality of care ${ }^{(16)}$, it becomes a crucial element in nursing care. In the interviewees' speeches, it was observed that safety permeated the humanized care to the hospitalized baby, in which the team aimed to raise the technical standard of care through the improvement of technical conduct and professional posture.

In this sense, it is perceived that the provision of neonatal care prioritizes interventions that consist of minimal handling, therapeutic positioning, maintenance of vital signs, especially body temperature and heated incubator, in addition to attention to neonatal environment. However, professionals verbalized the humanization of care and realized its importance in the daily practice of nursing.

A study carried out with the nursing team of a school hospital describes that caring should be a dynamic process that contemplates the singularities of the individual and the family in the therapeutic conduction. It should be emphasized that the essence of care should not be limited to the act of medicating, consulting and examining in healthdisease situations ${ }^{(4)}$. The humanization of care can be understood as the way of seeing and considering the human being from a global and holistic view.

In the present study, humanized care was also perceived by the nursing professionals' attitudes, based on aspects related to neonatal risks in the development of the baby. Among the speeches, there were questions related to measures to reduce pain and interventions to adjust the sensory environment of the unit.

It should be noted that the studied team showed to be aware of the changes emitted by the baby, through behavioral reactions such as crying, easy pain, irritability, increased heart and respiratory rate, oxygen hyposaturation and other signs. These results corroborate those found in other studies ${ }^{(17-18)}$, which highlight other reactions such as body movements, frowning brow and persistent crying, often related to pain.

The evaluation of pain and the interventions to alleviate it are responsibility of the nursing team; however, a recent study shows that in the home context, since mothers/caregivers are directly involved in the demand of care for special children, they recognize behavioral changes during pain sensations ${ }^{(19)}$.

The set of statements allows them to identify different actions of the professionals during the hospitalization of the baby in the neonatal unit. Such actions refer to daily care such as offering diet, bathing, changing diapers, as well as demonstrations of affection and warmth to the newborn and welcoming and supporting parents and family members. Welcoming means to receive, to protect, to support, that is, affective actions ${ }^{(3)}$. It is believed that the consolidation of humanization requires a commitment between professional, institution and client $^{(17) .}$

The nursing team recognized that the presence of parents contributes to the establishment of the affective bond between mother and child, promoting benefits for both. It has been shown that one of the forms of family participation is to be with the child, 
touching, caressing and talking with the child. These results are similar to the findings of other studies that value the presence and effective participation of parents in the care process ${ }^{(3,7-10)}$. The presence of a bond leads to an approximation of parents, allowing an authentic, affective and trusting relationship ${ }^{(4,9)}$.

Parental involvement during the child's hospitalization is a basic principle of child care, although it does not apply to neonatal units in all countries. In a study carried out in Mexico, parents found barriers that prevented them from participating as subjects in the care of the hospitalized child ${ }^{(16)}$. It is necessary to transform the philosophy of care, based on the perception of parents, with the right to participate in the process of hospitalization of the child.

These findings differ from the Brazilian situation, which already has a consolidated policy, which addresses the environment as a strategy of humanization and commitment to the three central axes: building space that aims at comfort, welcoming environments; production of subjectivities that involve the encounter of subjects - users, workers and managers, and that the environment can be used as a facilitating tool of the work process ${ }^{(17)}$.

Hospital environment refers to physical, social, professional space and interpersonal relationships involved with health care ${ }^{(17)}$. In this context, neonatal units are characterized as stressful places, due to the technological arsenal, excessive noise and brightness, temperature, and innumerable invasive and painful procedures, which make infants vulnerable and may imply damage to development $t^{(4,9,18)}$.

The effects caused by noise, alarm noise and brightness interfere with the physiological and behavioral stability of neonates, particularly in premature infants. These factors interfere with the non-applicability of humanized care, but are often due to the complexity of the neonatal intensive care units $^{(18-20)}$.

It is emphasized the importance of actions to reduce stressors ${ }^{(4,8,17,20)}$, as well as the need to develop new humanized strategies, making the neonatal environment more welcoming and less impersonal ${ }^{(4)}$. According to the participants' speeches, interventions were made to reduce brightness, noise, environmental stimulation, as well as there were measures to decrease handling and promote comfort, since they allow the regulation of body systems, as they reduce energy expenditure and accelerate the baby's weight gain $^{(8-9)}$, besides preserving the physical, psychic and social development ${ }^{(16)}$.

Despite the transformations in the care of newborn care, either due to technological innovations or in the perspective of inserting the family into the therapeutic process, it is observed that there is still need to minimize the negative impact of interventions inherent to the invasive and painful procedures, as well as the stress in the neonatal environment, which may bring sequels to the baby.

As limitations, the qualitative research method expresses the description of actions and language of the interviewees working in the neonatal unit, as well as the fact that the authors of this study are part of this team. The researcher's personal experiences are important elements in the analysis and understanding of the studied phenomena.

Despite the clarifications regarding anonymity and preservation on the application of the interview, it was noticed that the subjects did not talk about what they really think and do and did not criticize negatively certain attitudes and interventions applied in the unit. The difficulties encountered by choosing the qualitative research refer to the large amount of data collected, which implies in exhaustive work for analysis and interpretation.

In the quest for the quality of neonatal care, it is recognized that nursing practice has contributed as a support to professionals in the achievement of comprehensive, individual and humanized care for newborns and their families. From broad knowledge and professional awareness, it is possible to guarantee full assistance to the newborn and the parents, considering them as part of the unit of care. 
With the results of this study, it is possible to share experiences and new knowledge that address the construction and the meaning of comprehensiveness as guiding principle of health policies and practices.

\section{Conclusion}

This study made it possible to understand that the national humanization policy led to innovations in neonatal nursing care, creating a new and broad perspective on the practice of caring for newborns. Therefore, the acquisition of knowledge about humanized care implied the performance of the team with greater commitment, sensitivity and zeal in the art of caring, emphasizing, above all, actions of comfort, safety and welcome to the newborn and the family, as well as strategies related to sources of noise and stress in the neonatal environment.

\section{Collaborations}

Ferreira JHP and Amaral JJF contributed to the design, analysis and interpretation of data. Lopes MMCO contributed to the design of the project, essay writing, relevant and critical review of content and final approval of the version to be published.

\section{References}

1. Rubia ASC, Torati CV. Humanization in neonatal intensive care unit: a review. Rev Salus J Health Sci. 2016; 2(1):77-83.

2. Costa R, Padilha IM. Percepção da equipe de saúde sobre a família na UTI neonatal: resistência aos novos saberes. Rev Enferm UERJ. 2011; 19(2):2315.

3. Costa R, Klock P, Locks MOH. Acolhimento na unidade neonatal: percepção da equipe de enfermagem. Rev Enferm UERJ. 2012; 20(3):34953.
4. Lins RNP, Collet N, Cecchetti Vaz EM, Reichert APS. Percepção da equipe de Enfermagem acerca da humanização do cuidado na UTI Neonatal. R Bras Ci Saúde. 2013; 17(3):225-32.

5. Ministério da Saúde (BR). Secretaria de Atenção à Saúde. Política Nacional de Humanização. Brasília: Ministério da Saúde; 2013.

6. Ministério da Saúde (BR). Atenção humanizada ao recém-nascido de baixo peso: Método Canguru. Brasília: Ministério da Saúde; 2012.

7. Pott FS, Stahlhoefer T, Felix JVC, Meier MJ. Medidas de conforto e comunicação nas ações de cuidado de enfermagem ao paciente crítico. Rev Bras Enferm. 2013; 66(2):174-9.

8. Roseiro CP, Paula KMP. Concepções de humanização de profissionais em unidades de terapia intensiva neonatal. Estud. Psicol. 2015; 32(1):109-19.

9. Castro CM, Wichr P, Lima AMJ, Guedes HM. O estabelecimento do vínculo mãe/recém-nascido: percepções maternas e da equipe de enfermagem. R Enferm Cent 0 Min. 2012; 2(1):67-77.

10. Duarte ED, Sena RR, Dittz ES, Tavares TS, Lopes AFC, Silva PM. The role of the family in care delivery to hospitalized newborns: possibilities and challenges towards comprehensive care. Texto Contexto Enferm. 2012; 21(4):870-8.

11. Nogueira JWS, Rodrigues MCS. Comunicação efetiva no trabalho em equipe em saúde: desafio para a segurança do paciente. Cogitare Enferm. 2015; 20(3):636-40.

12. Grecco GM, Tsunemi MH, Balieiro MMFG, Kakehashi TY, Pinheiro EM. Repercussion of noise in the Neonatal Intensive Care Unit. Acta Paul Enferm. 2013; 26(1):1-7.

13. Gonçalves ITJP, Souza KV, Amaral MA, Oliveira ARS, Ferreira WFC. The embracement practice in prenatal care: limits, potentialities and contributions of nursing. Rev Rene. 2013; 14(3):620-9.

14. Bardin L. Análise de conteúdo. Lisboa: Edições 70; 2010. 
15. Fialho FA, Dias IMÁV, Santos RS, Silva LR, Salvador M. Humanization permeating newborn nursing care. Rev Enferm UFPE Online [Internet]. 2016 [citado 2016 jun. 21]; 10(7):2412-9. Disponível em: http://www.revista.ufpe.br/ revistaenfermagem/index.php/revista/article/ viewArticle/7112

16. Gallegos-Martínez J, Reyes-Hernández J, Scochi CGS. The hospitalized preterm newborn: The significance of parents' participation in the Neonatal Unit. Rev Latino-Am Enfermagem. 2013; 21(6):1360-6.

17. Ribeiro JP, Gomes GC, Thofehrn MB. Health facility environment as humanization strategy care in the pediatric unit: systematic review. Rev Esc Enferm USP. 2014; 48(3):527-36.
18. Mendes LC, Fontenele FC, Dodt RCM, Almeida LS, Cardoso MVLML, Silva CBG. Pain in the newborn within the Neonatal Intensive Care Unit. Rev Enferm UFPE Online. [Internet]. 2013 [citado 2016 jul. 14]; 7(11):6446-54. Disponível em: http://www.repositorio.ufc.br/bitstream/ riufc/8528/1/2013_art_fcfontenele.pdf

19. Lélis ALPA, Cardoso MVLML. Vivência das mães/ cuidadoras frente à dor da criança com paralisia cerebral. Cienc Cuid Saúde. 2014; 13(4):730-8.

20. Oliveira LL, Sanino GEC. A humanização da equipe de enfermagem em unidade de terapia intensiva neonatal: concepção, aplicabilidade e interferência na assistência humanizada. Rev Soc Bras Enferm Ped. 2011; 11(2):75-83. 